\title{
On the Atlantic cold tongue mode and the role of the Pacific ENSO
}

\section{R. A. F. De Almeida and P. Nobre}

National Institute for Space Research, Brazil

Received: 2 December 2011 - Accepted: 5 December 2011 - Published: 18 January 2012

Correspondence to: R. A. F. De Almeida (roberto@dealmeida.net)

Published by Copernicus Publications on behalf of the European Geosciences Union.

Atlantic cold tongue mode and the role of the Pacific ENSO

\section{R. A. F. De Almeida and} P. Nobre

\section{Title Page}

\section{Full Screen / Esc}

Printer-friendly Version

Interactive Discussion 


\section{Abstract}

The dominant mode of coupled ocean-atmosphere variability in the Tropical Atlantic is analysed in this work from a melange of datasets, focusing on the seasonal development and evolution of the Bjerknes feedback responsible for the generation of the

5 Atlantic cold tongue mode. The strength, seasonality and interannual variability of this mode is investigated through a joint EOF analysis of the anomalies of zonal wind velocity in the western basin together with sea surface temperature from the easternmost Tropical Atlantic, and analysed in conjunction with the depth of the $20^{\circ} \mathrm{C}$ isotherm, representing the three mechanisms responsible for the generation of the Bjerknes feedback. Results from the EOF analyses confirm the robustness and seasonality of the Atlantic cold tongue mode, with a positive feedback phase peaking during boreal summer when the Bjerknes feedback is stronger. Analysis of an event in 2005 shows that the positive feedback is followed by a negative feedback phase triggered by the wind field and driven by oceanic heat advection. More importantly, we investigated the lin15 earized impact of Niño events in the Pacific Ocean over the Atlantic by projecting the NINO 3.4 index over the Atlantic data. The Atlantic cold tongue mode has its variance reduced from $62 \%$ to $47 \%$ in the projected dataset, revealing that the Pacific ENSO has an inhibiting effect over its Atlantic counterpart.

\section{Introduction}

20 Modeling studies suggest that the coupled ocean-atmosphere variability of the Tropical Atlantic is dominated by a mode sustained by a positive feedback between sea surface temperature (SST) on the eastern part of the basin, trade winds over the western Atlantic, and the inclination of the equatorial thermocline (Zebiak, 1993). The so-called "cold tongue mode" is characterized during the cold SST phase by intensified trade winds and an anomalously tilted thermocline, shallower on the easternmost Atlantic and with positive heat content anomalies; this strongly coupled mode is analogous to
OSD

9, 163-185, 2012

\section{Atlantic cold tongue mode and the role of the Pacific ENSO}

\section{R. A. F. De Almeida and P. Nobre}

Title Page 
El Niño-Southern Oscillation (ENSO), although it displays a weaker feedback, explains less variance, and has a much shorter duration than its Pacific counterpart (Keenlyside and Latif, 2007).

The Bjerknes feedback responsible for the generation of the cold tongue mode ex5 hibits a strong seasonal cycle in the Atlantic, being stronger during boreal spring and summer (Keenlyside and Latif, 2007). In the Pacific, after the positive feedback period the SST pattern is eroded by a delayed negative ocean feedback, through the advection of heat content anomalies by ocean currents. The negative feedback provides the basis for predictability of ENSO events in the Pacific, and the same may be true 10 for analogous events in the Atlantic ocean. Understanding how the cold tongue mode evolves and is affected by remote variability is of great practical importance due to its impacts on precipitation over land (Wagner and da Silva, 1994).

The Atlantic cold tongue mode has been studied both through coupled modeling (e.g. Nobre et al., 2003) and data from reanalyses (e.g. Frankignoul and Kestenare, 15 2005), with only a few studies based on direct observations. Model biases, poor data quality, inadequate bulk algorithms and improper representation of the Atlantic climatology all contribute to create conflicting results. A better understanding of the oceanatmosphere interactions in this region would allow for model biases to be much smaller. It also remains to be investigated the existence of the delayed negative feedback in the 20 Tropical Atlantic and its implications for predictability; as well as how the cold tongue mode is influenced by others modes of variability, especially interactions between the Pacific and the Atlantic basins.

The variability of the tropical Atlantic Ocean has long been known to be affected by El Niño, although there exists an ambiguous and inconsistent relationship between Pacific and Atlantic Niños. Two different processes, induced by ENSO events in the Pacific Ocean, compete for a remote impact over the Atlantic basin of opposite signs. El Niño produces a warming signal in the troposphere that rapidly propagates eastward in the form of equatorial Kelvin waves, warming the tropical Atlantic in the absence of ocean dynamics. At the same time, modeling studies (Latif and Barnett, 1995) suggest that

\section{OSD}

$9,163-185,2012$

\section{Atlantic cold tongue mode and the role of the Pacific ENSO}
R. A. F. De Almeida and P. Nobre

Title Page

\section{4}


the tropical Atlantic basin can be cooled by easterly wind stress anomalies intensified by the Bjerknes feedback. The interaction between the tropospheric induced warming and the equatorial cooling results in a destructive interference process depicting a complex pattern of interaction between the Pacific ENSO and the Atlantic cold tongue 5 mode (Chang et al., 2006).

In this article we investigate the temporal variability of the Atlantic cold tongue, using observational data from a diversity of datasets, addressing the year-long evolution of the cold tongue mode. This includes the Optimal Interpolation SST (OISST) dataset, combining in situ and satellite SST interpolated onto a one-degree grid with weekly 10 resolution (Reynolds et al., 2002); the cross-calibrated, multi-platform (CCMP), multiinstrument ocean surface wind velocity dataset (Atlas et al., 1996); temperature profiles from Argo free-drifting profiling floats (Smith, 2000), used in order to estimate the depth of the $20^{\circ} \mathrm{C}$ isotherm (Z20); and current velocity from a moored Acoustic Doppler Current Profiler (ADCP) from the Prediction and Research Moored Array in the Tropical 15 Atlantic (PIRATA) Bourlès et al. (2008). In order to investigate the seasonal evolution of the Bjerknes feedback and the associated interannual variability, a variant of the joint EOF technique is introduced, allowing the characterization of the interannual variability of the different Atlantic ocean-atmosphere coupled modes, while describing their temporal evolution throughout the year.

The article is structured as follows. We present the data used in Sect. 2, also describing the time composition used for the joint EOF method. The coupled modes of ocean-atmosphere variability in the Tropical Atlantic are described in Sect. 3, investigating the influence of the Pacific ENSO over the Atlantic cold tongue mode. Discussion and conclusions are presented in Sect. 4.

\section{Data and methods}

The analysis in this work is based on the co-variability mechanisms that compose the Bjerknes feedback on the Tropical Atlantic, responsible for the generation of the cold

\section{OSD}

9, 163-185, 2012

\section{Atlantic cold tongue mode and the role of the Pacific ENSO}
R. A. F. De Almeida and P. Nobre

Title Page

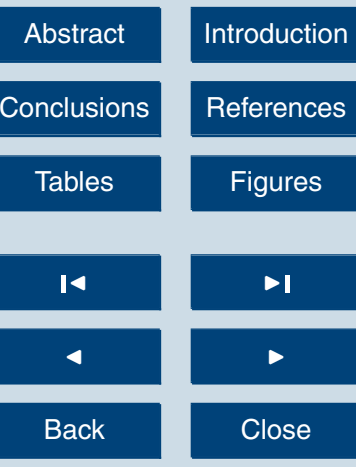

Full Screen / Esc

Printer-friendly Version

Interactive Discussion 
tongue mode. These include SST and heat content anomalies over the eastern part of the basin, together with zonal wind anomalies over the western Atlantic sector. Here we combine four datasets of different origin, mixing satellite and in-situ observations, increasing the confidence that any co-varing patterns that arise are robust and not 5 merely statistical artifacts of the technique.

\subsection{Observations}

For wind data we have used the CCMP multi-instrument ocean surface wind velocity dataset (Atlas et al., 1996). The 5-day gridded data covering the period between 5 July 1987 and 27 Decmeber 2009 were averaged over a box covering the western Atlantic 10 sector [the WAtl region from Keenlyside and Latif (2007)] over $3^{\circ} \mathrm{S}-3^{\circ} \mathrm{N}$ and $40^{\circ} \mathrm{W}-$ $20^{\circ} \mathrm{W}$. The resulting timeseries was then interpolated onto a regular time axis with 365 points per year. Figure 1a shows the zonal wind component (UWND) as colors; instead of being presented as a single timeseries the data has been reshaped as a 2-dimensional array by stacking individual years, with one axis depicting the seasonal evolution of the variable, and the other, the interannual variability. This reshaping is necessary for the joint EOF analysis, which will be described later. Averages along each of the axes show the seasonal cycle of the zonal wind (lower plot), as well as its interannual variability (right-side plot).

A similar figure is presented for the surface temperature data derived from the OISST dataset (Reynolds et al., 2002) (Fig. 1b). The weekly, one-degree grid resolution data is averaged over a box on the eastern Tropical Atlantic between $3^{\circ} \mathrm{S}-3^{\circ} \mathrm{N}$ and $0^{\circ} \mathrm{W}-$ $20^{\circ} \mathrm{W}$ [the Atlantic3 region defined in Keenlyside and Latif (2007)], covering the period from 1 January 1982 up to 31 December 2009, and also linearly interpolated onto a time axis with 365 equally spaced points per year. Since the SST timeseries has the 25 longest extension, this period was used as a basis for the analysis; this explains why the wind time axis in Fig. 1a also starts in 1982.

Figure 1C presents the timeseries for the depth of the $20^{\circ} \mathrm{C}$ isotherm $(Z 20)$ in the Atlantic3 sector, used as a proxy for the oceanic heat content. Here we have estimated
OSD

9, 163-185, 2012

\section{Atlantic cold tongue mode and the role of the Pacific ENSO}

\section{R. A. F. De Almeida and P. Nobre}

Title Page 
Z20 using temperature profiles from Argo free-drifting floats located in the Atlantic3 sector. The data covers the period between 28 July 1997 and 12 November 2010, and after Z20 was estimated the positions were regularly interpolated onto the 365-days time axis from 1 Janurary 1982 to 31 December 2009. Even though the Z20 timeseries

5 is short, noisy, and presents gaps, the Z20 information from the Argo drifters will be used to enhance the understanding of the evolution of the cold tongue mode.

In order to understand the delayed negative feedback of the cold tongue, we also analyse daily current velocity from a moored ADCP from PIRATA (Bourlès et al., 2008) located at $23^{\circ} \mathrm{W}$ in the equator, and subsurface profiles of temperature from two equa10 torial buoys at $35^{\circ} \mathrm{W}$ and $10^{\circ} \mathrm{W}$. The ADCP data from PIRATA covers only 3 discontiguous periods from 2002 to the present (Fig. 1d). Nevertheless, the data coverage is sufficient to illustrate how the ocean dynamics impacts the Atlantic Niños during the setdown of the cold tongue pattern. The temperature profiles were used to calculate the zonal temperature gradient along the equator, in order to estimate the advection of 15 heat content by the Equatorial Undercurrent (EUC). Like other timeseries, the ADCP and temperature data were interpolated onto a regular time axis with 365 points per year, allowing direct comparison with other datasets.

\subsection{EOF method}

Typically, the EOF analysis is performed on data arranged as 2-dimensional matrices, 20 with one axis corresponding to the location of the data in time, and the other, in space; this way of ordering data into a matrix is referred to as S-mode analyses (e.g. Venegas et al., 1997). The EOF method finds spatial patterns (eigenvectors) accompanied by expansion coefficients that describe how these patterns vary in time (eigenvalues). In this work we conduct the EOF analysis on the joint matrix resulted by combining the 2dimensional matrices of SST and UWND together, shown on Fig. 1. The resulting array has a "space" axis that corresponds to the seasonal evolution of the variables, and a "time" axis corresponding to the interannual variability. The resulting EOF analysis decomposes the data into maps depicting the seasonal evolution of the different modes

\section{OSD}

9, 163-185, 2012

\section{Atlantic cold tongue mode and the role of the Pacific ENSO}
R. A. F. De Almeida and P. Nobre

Title Page

\section{4}

Back

Close 
- the eigenvectors -, as well as timeseries that describe how they vary from year to year - the eigenvalues.

Three additional pre-processing steps were carried on the data before applying the EOF analysis. First, since we are not interested in the seasonal cycle of the joint 5 variables, we removed the average along the interannual axis from each variable (this corresponds to the plot showing the seasonal cycle on the bottom of Figs. 1-3). Otherwise the seasonal cycle would dominate the EOF analysis appearing as strong first mode of variability. Similarly, the average along the seasonal axes in each year (the right-side plot) was also removed from the data; this ensures that oscillating patterns

10 that are stationary throughout the year are also eliminated, removing from the results interannual and decadal modes of variability which have no interaction between ocean and atmosphere on seasonal timescales. From here on, when we mention SST, Z20 and UWND we are referring to these anomalies with relation to the seasonal and interannual cycles. Second, the timeseries were also smoothed with a moving square window of length 120, corresponding to approximately a third of a year in the regularly spaced time axis with 365 points. Finally, prior to the joint EOF each variable was normalized by its standard deviation, in order to give the same weight to each component of the Bjerknes feedback.

Due to the sparcity of the PIRATA data, anomalies from the climatology of ADCP and 20 ocean temperature from the $10^{\circ} \mathrm{W}, 23^{\circ} \mathrm{W}$ and $35^{\circ} \mathrm{W}$ buoys at the equator were calculated differently. The seasonal cycle of each variable and at each vertical level were estimated using a linear adjustment of annual and semi-annual frequencies, following the methodology from Podestá et al. (1991).

\section{OSD}

$9,163-185,2012$

\section{Atlantic cold tongue mode and the role of the Pacific ENSO}

\section{R. A. F. De Almeida and P. Nobre}

\section{Title Page}

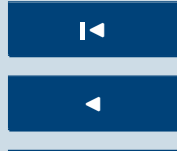

$\rightarrow 1$

Back

Close 


\section{Variability of the cold tongue mode}

\subsection{Joint EOF analysis}

The coupled ocean-atmosphere variability of the cold tongue mode is investigated by performing the joint EOF combining SST at the Atlantic3 sector with UWND at WAtl.

5 The initial analysis was conducted with joined SST and UWND, using data for the period between 1 January 1988 and 31 December 2008. This period was chosen in order to match these two corresponding datasets so that no gaps were present in either dataset; also, the last year from the dataset (2009) was removed due to missing values introduced by the 120-day moving average at the extremes of the timeseries.

10 The first two resulting modes explain more than $85 \%$ of the total variance, with the dominant mode accounting for almost $70 \%$ of the variability $(69.88 \%$ and $15.56 \%$, respectively). This high fraction is expected from the way the data was constrained, joining different variables together and eliminating the seasonal cycle and long-term oscillations. Figure 2 shows the first two modes of variability from the joint SST + UWND EOF analysis; maps and expansion coefficients are normalized to one standard deviation. The first mode clearly illustrates the mechanisms behind the Bjerknes feedback, generating the cold tongue mode: in February the easterly trade winds over the western Atlantic start to intensify, resulting in a decrease of SST over the eastern part of the basin, with a 1-month lag (Fig. 2a). The cold tongue peaks in June, and after

20 its development the Tropical Atlantic displays warmer waters and weaker winds at the end of the year. During the onset and setdown of the Bjerknes feedback the western zonal wind precedes variations in the eastern SST by a month, agreeing with observations (Servain et al., 1982). This pattern of seasonal evolution varies on interannual timescales, as depicted by its expansion coefficients (solid line in Fig. 2c).

25 One important point to note is that the first EOF is not cyclic. After the development of the cold tongue the Atlantic is warmer and has weaker easterlies winds by December, suggesting that this first mode leaves the Tropical Atlantic in a state different from the begining of the year. The second EOF (Fig. 2b), explaining $15 \%$ of the

\section{Atlantic cold tongue mode and the role of the Pacific ENSO}
R. A. F. De Almeida and P. Nobre

Title Page 
total variance, appears as a mechanism to return the Tropical Atlantic to its baseline state. The seasonal evolution of EOF 2 reveals weak winds and warm SST during the begining of the year. These anomalies are damped throughout the year, displaying a small amplitude at the end of the year. The expansion coefficients of the second mode 5 also show variability on interannual timescales (dotted line in Fig. 2c). The mode has a strong expression after the strong cold tongue in 1997 and a warm event in 1996 (PC 2 on Fig. 2c), confirming that the second EOF acts in order to restore the anomalies back to zero after a strong cold tongue event. Here only the first and second modes are analysed due to the fact the the third and subsequent EOFs are not statistically significant according to the rule of thumb by North et al. (1982).

\subsection{ENSO-related and local variability}

Modeling studies suggest that the variability of the Atlantic cold tongue mode can be remotely modulated from the Pacific ocean, but also generated by local oceanatmosphere dynamics in the Tropical Atlantic (Nobre et al., 2003), resulting in independent modes of variability that can interfere with each other (Chang et al., 2006). The joint EOF analysis as performed in the last section is unable to separate between these two different patterns due to the constraining orthogonality of the resulting modes, since the modes share the same seasonal ocean-atmosphere interaction patterns (the eigenvectors of the EOF analysis).

20 To investigate the separation between a local and a remotely-forced cold tongue mode we generated a new dataset representing the linearized effect of the Pacific ENSO over the Tropical Atlantic. In order to do this a monthly NINO 3.4 index was averaged from July to June, resulting in an yearly timeseries from 1982 to 2009 . This timeseries was projected onto the yearly axis of the 2-dimensional arrays of SST and

UWND; since UWND starts in 1988 the first $6 \mathrm{yr}$ of the dataset were padded with zeros. The result is a new dataset with only the direct influence of Pacific Niños. Note that this projection was performed assuming a priori that there is a lag relationship where Pacific Niños precede the Atlantic cold tongue mode by 6 months: an ENSO peaking in

OSD

$9,163-185,2012$

\section{Atlantic cold tongue mode and the role of the Pacific ENSO}

R. A. F. De Almeida and P. Nobre

Title Page

Abstract Introduction

Conclusions

Tables

References

Figures

14

$\rightarrow 1$

4

Back

Close

Printer-friendly Version

Interactive Discussion 
December would have an impact on the Atlantic Bjerknes feedback that peaks during boreal summer of the following year. Nevertheless, it may be the case that Tropical Atlantic SSTs have an impact over Pacific ENSO, especially in the last few decades (Keenlyside and Latif, 2007).

5 The difference between the ENSO-projected data and the original datasets represents the variability of the Tropical Atlantic without the linearized impact of the Pacific Niños; this second dataset was used to investigate the local variability of the Bjerknes feedback, although it may include the remote effects of other modes of variability. The projected ENSO dataset and the difference from the original data will be referred to as 10 remote and local datasets, respectively.

We conducted the joint EOF analysis on both these datasets, and the results are shown on Fig. 3. Both datasets exhibit the Bjerknes feedback mechanism as the first mode: a cold tongue stronger during boreal summer, led by the progressive strengthening of the trade winds. The local mode appears as a more robust feature when 15 compared to the remotely forced one, explaining more than $62 \%$ of the variance, versus $47 \%$ for the remote mode. It is interesting to note that even though this analysis shows that ENSO is capable of exciting the Bjerknes feedback over the Tropical Atlantic, not all Niños in the Pacific have an impact over the Atlantic cold tongue mode. The expansion coefficients from the remote mode show (Fig. 3c, dotted line) that there 20 is no response in the Atlantic to the strong El Niño of 1997/1998, e.g. neither by the remote nor the local mode. This is consistent with the analyses of Chang et al. (2006) on the interference between atmospheric and oceanic processes over the Tropical Atlantic in response to El Niño.

From Fig. $3 \mathrm{c}$ it is possible to see that the 1982/1983 El Niño had an impact over the 25 Tropical cold tongue mode, while the local mode was almost zero, also in agreement with the results from Chang et al. (2006). This interference between the locally excited Bjerknes feedback and the remotely forced mode can be investigated from the combined expansion coefficients of the local and remote joint EOF analyses, i.e. the sum of the normalized PC 1 from the local dataset with $P C 1$ from the remote dataset. This

\section{OSD}

9, 163-185, 2012

\section{Atlantic cold tongue mode and the role of the Pacific ENSO}

\section{R. A. F. De Almeida and P. Nobre}

Title Page 
index is well correlated $(r=0.90)$ with the expansion coefficients from the full joint EOF 1 of SST+UWND (Fig. 4). This suggests that the cold tongue mode found in the initial joint EOF analysis can be separated into a remote and a local mode. The interaction of these two modes determine the strength and sign of the Bjerknes feedback in the

5 Tropical Atlantic. Table 1 shows the values of the index calculated for the full joint EOF, together with the eigenvalues from the remote and local modes.

One interesting result of the separation analysis is that the variability explained by the cold tongue mode in the remote dataset is reduced to only $47 \%$, suggesting that that Pacific El Niño has an inhibiting impact over the Atlantic cold tongue mode. This 10 hypothesis was investigated through a Monte Carlo test, by repeating the EOF analysis on datasets obtained by projecting 10000 random timeseries with the same standard deviation and lag-1 autocorrelation of the yearly NINO 3.4 index. The resulting modes from the random datasets explain significantly $(p=0.995)$ more variance than the ENSO-projected dataset, confirming that the Atlantic cold tongue mode has its

\subsection{The negative feedback}

The cold tongue mode is characterized by two different phases: first, a positive feedback phase, during the first half of the year, during which anomalies of SST and UWND grow, reaching their maximum amplitude during boreal summer. After peaking the 20 cold tongue mode is destroyed by a negative feedback where subsurface temperature anomalies are able to affect eastern SSTs, reverting the initial surface signal. In the Pacific, this feedback is triggered by the oceanic advection of heat content $(\mathrm{HC})$ by the EUC, constituting an essential ingredient of ENSO and providing a basis for predictability of ENSO events (Keenlyside and Latif, 2007).

25 In order to investigate the negative feedback and determine if ocean dynamics are important to destroy the Atlantic cold tongue we looked at ADCP data and temperature profiles from three PIRATA buoys located at the equator. This analysis is limited by the availability of ADCP data. The moored ADCP has uninterrupted coverage of the

\section{OSD}

9, 163-185, 2012

\section{Atlantic cold tongue mode and the role of the Pacific ENSO}
R. A. F. De Almeida and P. Nobre

Title Page

\section{4}

Back

Close 
zonal and meridional currents at $0^{\circ} \mathrm{N} / 23^{\circ} \mathrm{W}$ for the years of 2002, 2008 and 2009. Unfortunately, as we can see on the Atlantic cold tongue index (Fig. 4), 2002 and 2008 are characterized by a small amplitude of the Bjerknes feedback; also, 2009 is missing from the analysis due to the moving average procedure. This way, to investigate the 5 evolution of a cold tongue event we were limited to use the incomplete ADCP data for the year of 2005. While the data coverage in this year is limited only to the second half of the year, this is the period when the negative feedback should be acting over the ENSO pattern in the Atlantic, so the data may be used to study a particular realization of the cold tongue mode.

10 The temperature profiles from the buoys at $0^{\circ} \mathrm{N} / 35^{\circ} \mathrm{W}$ and $0^{\circ} \mathrm{N} / 10^{\circ} \mathrm{W}$ were used to estimate the zonal temperature gradient along the equator. Combined with the ADCP zonal velocity the data was used as a first order estimate of the heat advection along the equator in the Tropical Atlantic:

$-u \frac{\delta T}{\delta x} \approx-\bar{U} \frac{\Delta T}{\Delta x}$

15 This approximated timeseries of heat transport is most probably a superestimation of the actual heat advection, since the eastward flowing EUC becomes shallower as it crosses the Atlantic, so that the water transport is not purely horizontal. Nevertheless, since the PIRATA ADCP data lacks vertical velocity, the temperature advection was estimated assuming that the heat is carried along layers of constant depth.

Figure 5 shows the behavior of the Tropical Atlantic during the year of 2005 . The anomalous temperature advection estimated from PIRATA buoys is plotted as colors in a XZ section. Anomalies of SST (solid line), UWND (dotted), wind speed (WSPD, dash-dotted) and Z20 (dashed) are overlayed after being normalized by their respective standard deviations, on the right y-axis. The anomalies of SST and UWND depict the evolution of the Bjerknes feedback similar to the maps produced by the joint EOF analysis, with the wind leading SST by 1 month, and a cold tongue developing and peaking during June.

OSD

9, 163-185, 2012

\section{Atlantic cold tongue mode and the role of the Pacific ENSO}

R. A. F. De Almeida and P. Nobre

Title Page

Abstract Introduction

Conclusions

References

Tables Figures

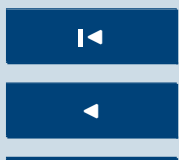

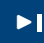

Back

Close

Printer-friendly Version

Interactive Discussion 
The analysis of the Tropical Atlantic in 2005 show that during the development of the cold tongue there is a decrease of $\mathrm{HC}$ in the eastern part of the basin; the $20^{\circ} \mathrm{C}$ isotherm becomes shallower during boreal spring due to the strenghtening of the trade winds. After the cold tongue peaks in the boreal summer there is a strong eastward 5 transport of heat, generated both by an intensification and deepening of the EUC, as well as the development of a stronger zonal temperature gradient (not shown). The heat transport is accompanied by an increase in $\mathrm{HC}$ in the Atlantic3 region and a deepening of Z20.

Even though the observed heat advection is consistent with the theory of a negative 10 feedback involving ocean dynamics, the data for 2005 and the results from the joint EOF suggest that the eastern SST leads the increase in $\mathrm{HC}$ due to the relaxation of the trade winds. There is a 1 month lag between SST and Z20 after the cold tongue reaches its maximum amplitude in June. A lagged correlation analysis (not shown) reveals a maximum when SST leads by 15 days in 2005 . This suggests that the negative 15 feedback is initially triggered by the atmosphere, with ocean dynamics acting only later throughout the year. The analysis of the total wind speed in the Atlantic3 sector for 2005 shows a weakening starting in April (dot-dashed line), when the ITCZ starts its northward migration. The reduction in wind speed could initiate the destruction of the cold tongue mode through the decrease of wind mixing and upwelling, resulting in the warming of the surface waters.

\section{Conclusions}

In this work we used observational data to analyse the covariability of the three elements that compose the Bjerknes feedback responsible for the Atlantic cold tongue mode: the trade winds over the western part of the basin, and SST and heat conperformed by a variant of the joint EOF technique where the data were composed along a seasonal and an interannual axis. The resulting EOF modes describe how

OSD

9, 163-185, 2012

\section{Atlantic cold tongue mode and the role of the Pacific ENSO}

\section{R. A. F. De Almeida and P. Nobre}

Title Page 
the ocean-atmosphere interactions evolve throughout the year, together with the yearto-year variability of the cold tongue mode. The joint EOF analysis confirmed that the Bjerknes feedback is a robust feature of the Tropical Atlantic. These results are in agreement with the current knowledge of the Atlantic cold tongue mode (Latif and 5 Grötzner, 2000, e.g.), indicating that the proposed EOF technique is a valid tool to study seasonal patterns of variability.

It is well known that the Atlantic cold tongue can be influenced by other remote modes of variability (Keenlyside and Latif, 2007), although the specific mechanisms still remain unknown. The initial analyses that motivated this work suggested the existence of two separate modes of variability of the Bjerknes feedback in the Tropical Atlantic: a remotely forced mode correlated with the Pacific NINO 3.4 index, and a second mode of local variability excited by internal dynamics. The leading modes of the NINO 3.4 projected datasets and its residual reveal the same pattern of the Bjerknes feedback, supporting our hypothesis that the Atlantic cold tongue is both influenced by the Pacific 15 basin as well as generated locally.

While this indicates that the Pacific has an impact over the Tropical Atlantic, the cold tongue mode has its variability significantly reduced to $47 \%$. This is an indication that Pacific ENSO has a dominant impact that acts to inhibit the cold tongue mode in the tropical Atlantic. This is true, e.g. for the particularly strong event of 1997/1998, which has no expression over the Tropical Atlantic cold tongue mode. It is known that Pacific Niños are sometimes unable to influence the winds in the western equatorial Atlantic. (Chang et al., 2006) hypothesize that this may be related to the pre-existing tropical Atlantic SST condition prior to an EI Niño. This can be observed in the EOF 2 obtained from the complete dataset (Fig. 2) by reconstructing the signal: the expansion coefficient PC 2 (dotted line) has a high loading in 1998, that when combined with the map of EOF 2 reveals warmer than normal SST and weaker trade winds in the beginning of 1998. In this event, not only the Pacific-induced Bjerknes is inhibited, but also the local mode. Both modes have expansion coefficients that are close to zero in 1998 , suggesting that the absence of the cold tongue in this year is not the result of the
OSD

9, 163-185, 2012

\section{Atlantic cold tongue mode and the role of the Pacific ENSO}

\section{R. A. F. De Almeida and P. Nobre}

Title Page 
interference between the local and the remote mode, but a consequence of the initial conditions in the basin unfavorable for the development of the feedback.

Using ADCP data from the PIRATA buoys we also investigated the delayed negative feedback responsible for the setdown of the cold tongue mode after the positive Bjerk5 nes feedback. The limited data available restricted our analysis to a single event of a strong cold tongue in 2005. At the begining of the year the Tropical Atlantic displays stronger trade winds, followed by the development of a cold SST tongue and the shallowing of Z20 in the eastern Tropical Atlantic. The damping of the cold tongue is driven initially not by changes in heat content, since SST leads changes in Z20 by 15 days. 10 Instead, the reduction of the SST anomaly is led by changes in wind speed associated with the northward migration of the ITCZ. The reduction in wind speed tends to increase the SST, destroying the cold anomaly; while the shift of the ITCZ makes the zonal wind over WAtl insensitive to variations in SST. Nevertheless, the advection of anomalous heat by the EUC plays a role in destroying the cold tongue mode, but only 5 after the positive feedback has ended (Fig. 5a).

In spite of the sparseness of the ocean data from PIRATA, this analysis suggests that there may be different triggers for the negative feedback that terminates the cold tongue mode in the Tropical Atlantic. For a better understanding of the delayed negative feedback in the Tropical Atlantic, modeling efforts are of extreme importance. The results presented in this article will work as a basis for a future modeling study that will investigate the different triggers of the delayed negative feedback, considering the full heat budget of the Tropical Atlantic. The use of a coupled ocean-atmosphere model will also make it possible to understand the mechanisms through which the cold tongue mode can be influenced by Pacific-Atlantic interactions, as well as by the local variability of the basin.

Acknowledgements. We would like to thank the International Argo Program and the national programs that contribute to it for the Argo drifer data (http://www.argo.ucsd.edu, http://argo. jcommops.org); NOAA/OAR/ESRL PSD, Boulder, Colorado, USA, for the NOAA_OI_SST_V2 data (http://www.esrl.noaa.gov/psd/); TAO Project Office of NOAA/PMEL for the PIRATA data

\section{OSD}

9, 163-185, 2012

\section{Atlantic cold tongue mode and the role of the Pacific ENSO}
R. A. F. De Almeida and P. Nobre

Title Page

\section{4}

Back

Close 
(http://www.pmel.noaa.gov/tao/data_deliv/deliv-pir.html); and PO.DAAC/JPL/NASA for CCMP data (http://podaac.jpl.nasa.gov/datasetlist?search=ccmp).

\section{OSD}

$9,163-185,2012$

\section{References}

Atlas, R., Hoffman, R. N., Bloom, S. C., Jusem, J. C., and Ardizzone, J.: A Multiyear Global Surface Wind Velocity Dataset Using SSM/I Wind Observations, B. Am. Meteorol. Soc., 77, 869-882, doi:10.1175/1520-0477(1996)077<0869:AMGSWV>2.0.CO;2, 1996. 166, 167

Bourlès, B., Lumpkin, R., McPhaden, M. J., Hernandez, F., Nobre, P., Campos, E., Yu, L., Planton, S., Busalacchi, A., Moura, A. D., Servain, J., and Trotte, J.: The Pirata Program: History, Accomplishments, and Future Directions, B. Am. Meteorol. Soc., 89, 1111-1125, 2008. 166, 168

Chang, P., Fang, Y., Saravanan, R., Ji, L., and Seidel, H.: The cause of the fragile relationship between the Pacific El Niño and the Atlantic Niño, Nature, 443, 3248, http://www.biomedsearch.com/nih/cause-fragile-relationship-between-Pacific/16988709. html, 2006. 166, 171, 172, 176

15 Frankignoul, C. and Kestenare, E.: Air-Sea Interactions in the Tropical Atlantic: A View Based on Lagged Rotated Maximum Covariance Analysis, J. Climate, 18, 3874-3890, 2005. 165

Keenlyside, N. S. and Latif, M.: Understanding Equatorial Atlantic Interannual Variability, J. Climate, 20, 131-142, doi:10.1175/JCLI3992.1, 2007. 165, 167, 172, 173, 176

Latif, M. and Barnett, T. P.: Interactions of the Tropical Oceans., J. Climate, 8, 952-968, doi:10.1175/1520-0442(1995)008<0952:IOTTO>2.0.CO;2, 1995. 165

Latif, M. and Grötzner, A.: The equatorial Atlantic oscillation and its response to ENSO, Clim. Dynam., 16, 213-218, doi:10.1007/s003820050014, 2000. 176

Nobre, P., Zebiak, S. E., and Kirtman, B. P.: Local and remote sources of tropical atlantic variability as inferred from the results of a hybrid ocean-atmosphere coupled model, Geophys.

25 Res. Lett., 30, 8008, doi:10.1029/2002GL015785, 2003. 165, 171

North, G. R., Bell, T. L., Calahan, R. F., and Moeng, F. J.: Sampling Error in the Estimation of Empirical Orthogonal Functions., Mon. Weather Rev., 110, 699-706, 1982. 171

Podestá, G. P., Brown, O. B., and Evans, R. H.: The Annual Cycle of Satellite-derived Sea Surface Temperature in the Southwestern Atlantic Ocean, J. Climate, 4, 457-467, 1991.

\section{Atlantic cold tongue mode and the role of the Pacific ENSO}

\section{R. A. F. De Almeida and P. Nobre}

Title Page

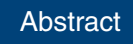

Introduction

Conclusions

References

Tables

Figures

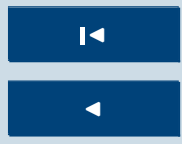

$>1$

Back

Close
Printer-friendly Version

Interactive Discussion 
Reynolds, R. W., Rayner, N. A., Smith, T. M., Stokes, D. C., and Wang, W.: An Improved In Situ and Satellite SST Analysis for Climate., J. Climate, 15, 1609-1625, doi:10.1175/15200442(2002)015<1609:AlISAS>2.0.CO;2, 2002. 166, 167

Servain, J., Picaut, J., and Merle, J.: Evidence of remote forcing in the equatorial Atlantic Ocean, J. Phys. Oceanogr., 12, 457-63, 1982. 170

Smith, N. R.: The Global Ocean Data Assimilation Experiment, Advances in Space Research, 25, 1089-1098, doi:10.1016/S0273-1177(99)00868-6, 2000. 166

Venegas, S. A., Mysak, L. A., and Straub, D. N.: Atmosphere-Ocean Coupled Variability in the South Atlantic., J. Climate, 10, 2904-2920, 1997. 168

10 Wagner, R. G. and da Silva, A. M.: Surface conditions associated with anomalous rainfall in the Guinea coastal region, Int. J. Climatol., 14, 179-199, 1994. 165

Zebiak, S. E.: Air-Sea Interaction in the Equatorial Atlantic Region., J. Climate, 6, 1567-1586, 1993. 164

\section{OSD}

9, 163-185, 2012

\section{Atlantic cold tongue mode and the role of the Pacific ENSO}

R. A. F. De Almeida and

P. Nobre

Title Page

Abstract

Introduction

Conclusions

References

Tables

Figures

14

4

Back

Full Screen / Esc

Printer-friendly Version

Interactive Discussion 
Table 1. Eigenvalues for the joint EOF of SST+UWND anomalies from the original dataset (Full), the linearized ENSO projected dataset (Remote) and the local dataset (Local), together with the sum of Remote+Local.

\begin{tabular}{rrrrr}
\hline Year & Full & Remote & Local & Sum \\
\hline 1983 & 0.39 & 1.18 & -0.18 & 1.00 \\
1984 & 0.08 & -0.61 & 0.47 & -0.14 \\
1985 & 0.03 & -0.72 & 0.44 & -0.29 \\
1986 & -0.74 & -0.43 & -0.55 & -0.98 \\
1987 & 0.62 & -0.14 & 0.25 & 0.10 \\
1988 & -1.15 & -1.77 & -0.19 & -1.96 \\
1989 & -0.83 & 1.30 & -1.51 & -0.20 \\
1990 & 0.73 & -0.60 & 1.10 & 0.50 \\
1991 & -1.44 & -1.42 & -0.68 & -2.10 \\
1992 & 1.06 & 2.35 & -0.02 & 2.33 \\
1993 & 1.36 & 0.09 & 1.20 & 1.28 \\
1994 & 0.36 & -0.33 & 0.58 & 0.25 \\
1995 & -1.29 & -1.73 & -0.26 & -2.00 \\
1996 & -2.33 & 1.56 & -3.13 & -1.57 \\
1997 & 1.96 & -0.39 & 2.09 & 1.70 \\
1998 & -0.06 & -0.03 & 0.07 & 0.04 \\
1999 & -0.77 & 1.25 & -1.33 & -0.08 \\
2000 & -0.34 & -0.37 & -0.24 & -0.62 \\
2001 & -0.64 & -0.29 & -0.51 & -0.81 \\
2002 & -0.23 & -0.65 & 0.14 & -0.51 \\
2003 & 0.78 & 0.66 & 0.43 & 1.09 \\
2004 & 1.35 & 0.21 & 1.21 & 1.42 \\
2005 & 1.47 & 1.27 & 0.82 & 2.08 \\
2006 & -0.04 & -0.58 & 0.29 & -0.30 \\
2007 & 0.28 & -0.34 & 0.31 & -0.03 \\
2008 & -0.61 & 0.57 & -0.78 & -0.21 \\
\hline & & & &
\end{tabular}

OSD

9, 163-185, 2012

\section{Atlantic cold tongue mode and the role of the Pacific ENSO}

R. A. F. De Almeida and P. Nobre

Title Page

Abstract

Introduction

Conclusions

References

Tables

Figures

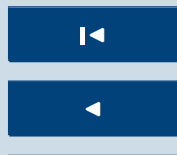

$\Delta$

Back

Close

Full Screen / Esc

Printer-friendly Version

Interactive Discussion 
A CCMP zonal wind at WAtl

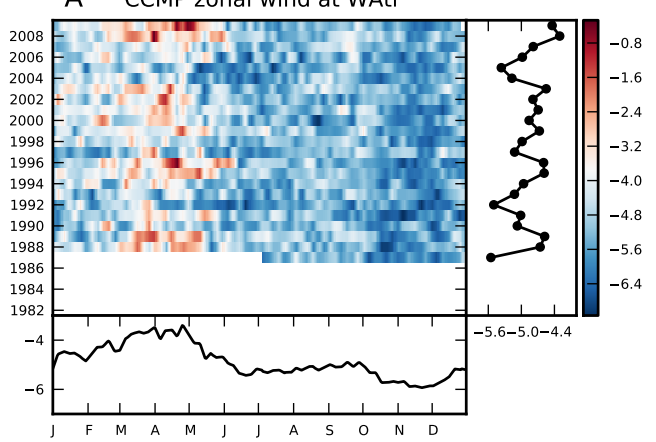

C Depth of $\mathbf{Z 2 0}$ at Atlantic3

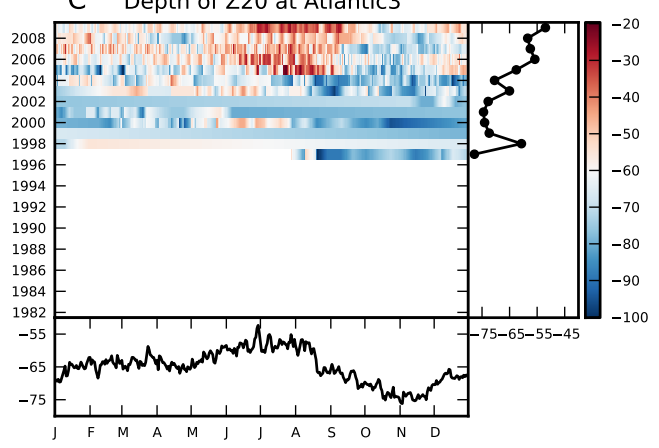

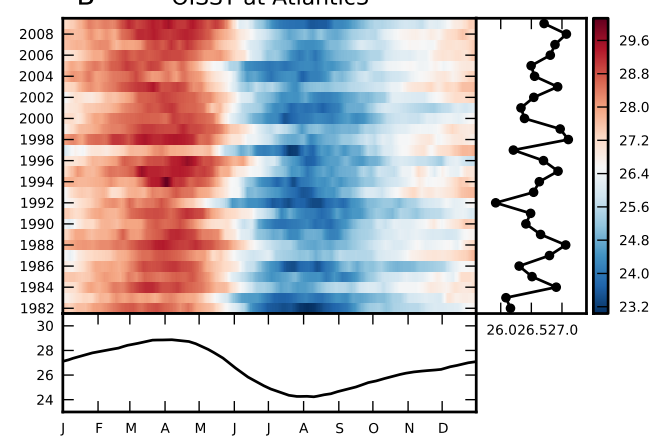

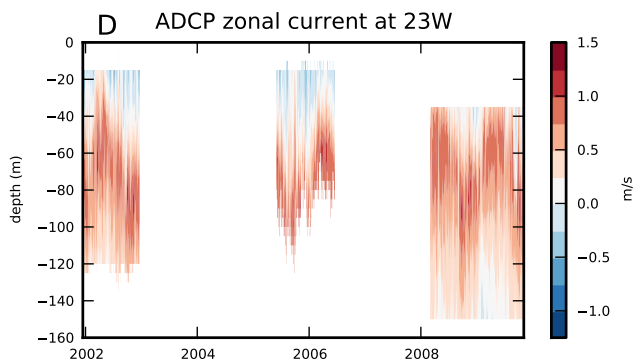

OSD

9, 163-185, 2012

Atlantic cold tongue mode and the role of the Pacific ENSO

R. A. F. De Almeida and P. Nobre

Title Page

Abstract

Conclusions

Tables

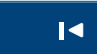

4

Back

References

Figures

\section{Full Screen / Esc}

Printer-friendly Version

Interactive Discussion 
Joint EOF SST [Atlantic3] and UWND [WAtI]
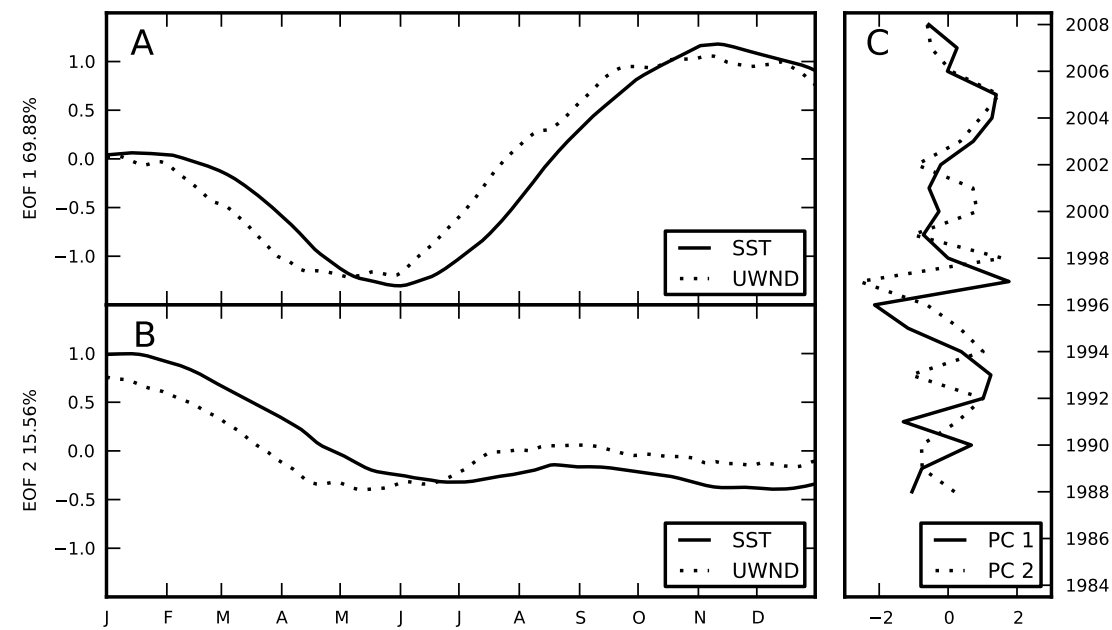

Fig. 2. (a) First EOF map from the joint analysis of SST and UWND for the period between 1 January 1988 and 31 December 2008, explaining $69.88 \%$ of the variance. The solid line shows the evolution of SST in the Atlantic3 section throughout the year, while the dotted line represents UWND at the WAtl region. (b) Same for the second EOF, accounting for $15.56 \%$ of the total variance. (c) Expansion coefficients of the first two EOFs; the solid line represents PC 1, while the dashed line, PC 2. The expansion coefficients depict how the intensity of the patterns of intra-annual interactions depicted in (a) and (b) vary from year-to-year.

\section{Atlantic cold tongue mode and the role of the Pacific ENSO}

R. A. F. De Almeida and P. Nobre

\section{Title Page}

\section{Abstract}

Introduction

Conclusions

References

\section{Tables}

Figures

14

4

Back

Close

Full Screen / Esc

Printer-friendly Version

Interactive Discussion 


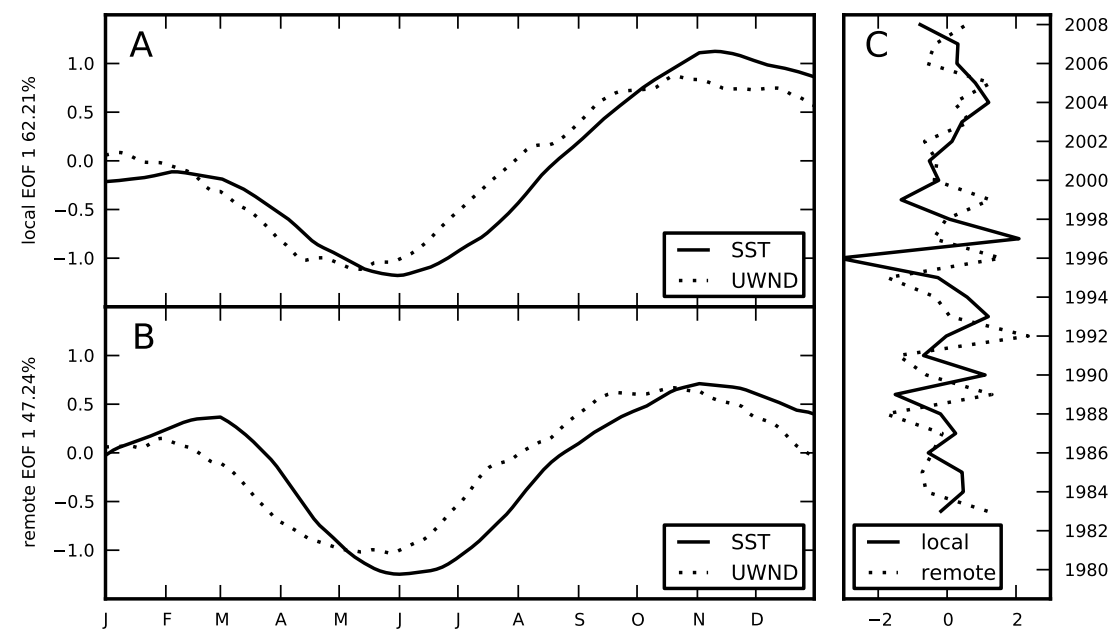

Fig. 3. (a) First EOF map from the joint analysis of SST and UWND carried on the local dataset, without the direct influence of Pacific ENSO for the period between 1 January 1983 and 31 December 2008. UWND was padded with zeros frmo 1983 to 1988. The mode explains $62.21 \%$ of the total variance. The solid line shows the evolution of SST in the Atlantic3 section throughout the year, while the dotted line represents UWND at the WAtl region. (b) Same for the first EOF of the remote dataset, obtained by projecting the NINO 3.4 index onto the data, explaining $47.24 \%$ of the variance. (c) Expansion coefficients for the EOF maps of (a) and (b).
9, 163-185, 2012

\section{Atlantic cold tongue mode and the role of the Pacific ENSO}

\section{R. A. F. De Almeida and} P. Nobre

\section{Title Page}

\section{Abstract}

Introduction

Conclusions

References

Tables

Figures

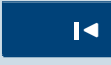

4

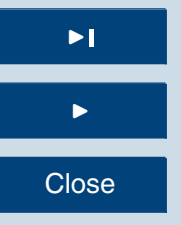

Back

Close

\section{Full Screen / Esc}

Printer-friendly Version

Interactive Discussion 


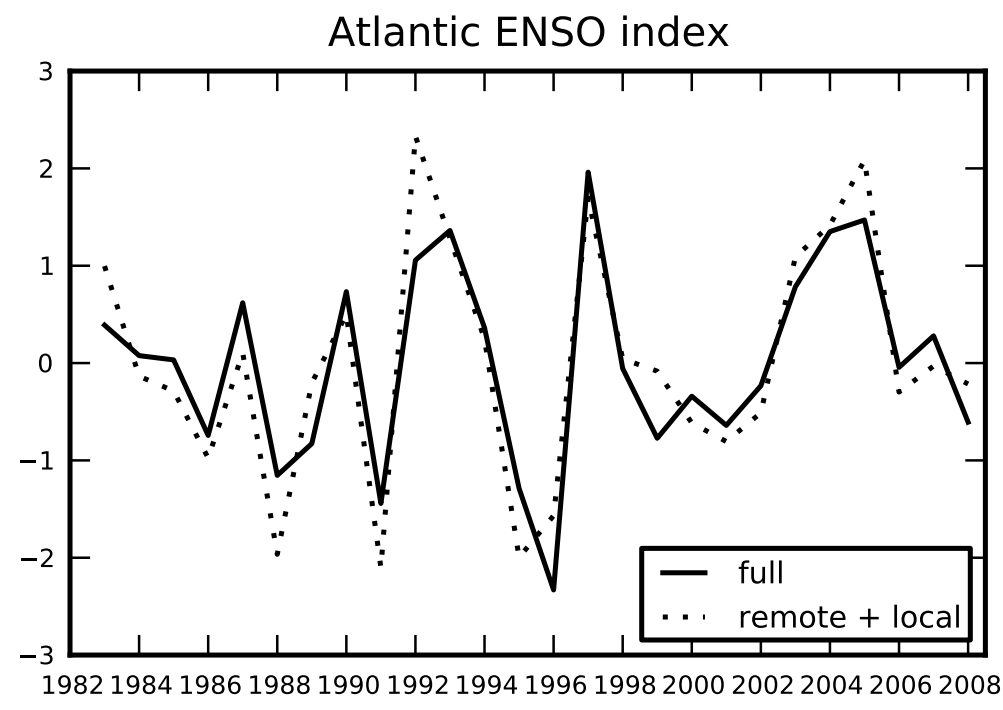

Fig. 4. An Atlantic cold tongue index. The solid line corresponds to the PC 1 of the joint EOF of SST and UWND for the period between 1 January 1983 and 31 December 2008. The dotted line corresponds to the sum of PC 1 of the local mode with PC 1 of the remote mode (Fig. 3c), showing that both modes combine to form the observed Atlantic cold tongue mode.

\section{Atlantic cold tongue mode and the role of the Pacific ENSO}

R. A. F. De Almeida and P. Nobre

Title Page

Abstract

Introduction

Conclusions

References

Tables

Figures

14

4

Back

Close

Full Screen / Esc

Printer-friendly Version

Interactive Discussion 


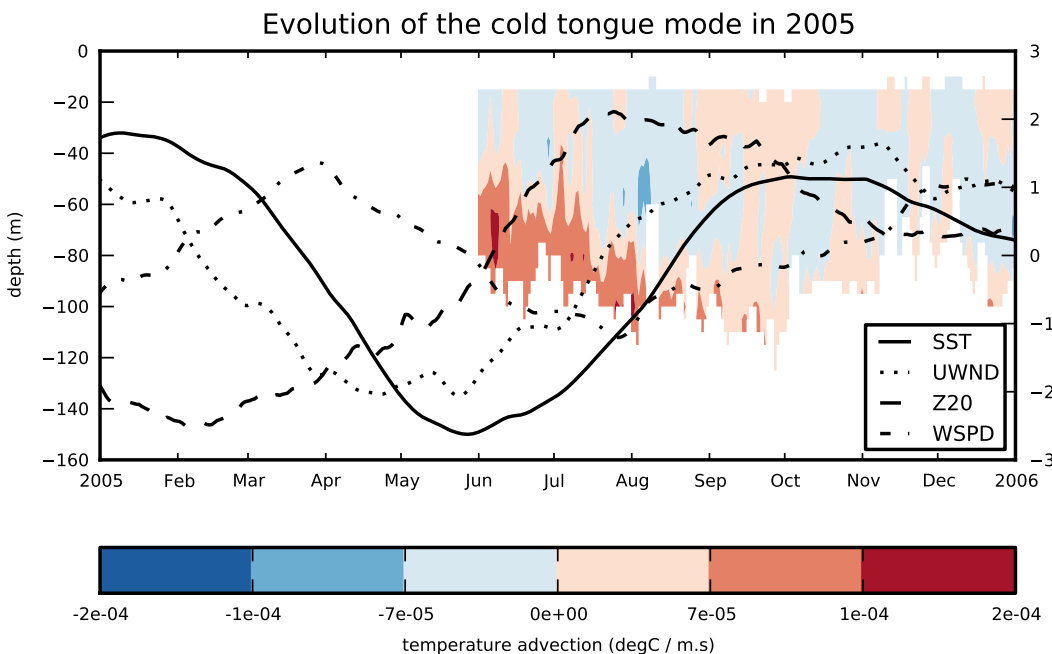

\section{Atlantic cold tongue mode and the role of the Pacific ENSO}

R. A. F. De Almeida and P. Nobre

Title Page

\section{Abstract}

Conclusions

\section{Tables}

Fig. 5. Evolution of the cold tongue event of 2005. The colors show a depth-time section of the estimated anomalous temperature advection, calculated using PIRATA data. The lines show anomalies of SST (solid), UWND (dotted), Z20 (dashed) and wind speed (dash-dotted) throughout the year, in standard deviations (right axis).
14

4

\section{Back}

Introduction

\section{References}

\section{Figures}

\section{Full Screen / Esc}

Printer-friendly Version

Interactive Discussion 